\title{
ハンドアイビジョンシステムのための近似型窺司見動作制御法
}

\author{
学生員 市川麻理子* 正 員 柴田 昌明*
}

\section{Approximate Exploring Motion Control for Eye-in-Hand Visual Servoing}

Mariko Ichikawa*, Student Member, Masaaki Shibata*, Member

This paper proposes a visual servo control method for exploring motion of eye-in-hand robot to recognize a threedimensional object. Optimal motion is based on the strategy in which the position estimation precision of the feature points gets improved when the feature points move widely, and the optimal robot motion provides the widest transitions of the feature points per unit robot motion, so that the robot should be controlled to purse such motion. In addition, this paper describes the way to reduce a large number of calculation efforts. The validity of our approach is confirmed in the several experimental results.

キーワード：近似型窥悓動作制御，ビジュアルサーボ，ハンドアイロボット，物体認識

Keywords: approximate exploring motion control, visual servo control, eye-in-hand robot, object recognition

\section{1. 序 論}

近年，ハンドアイロボットによる物体認識手法について 多くのさまざまな研究が行われている(1)。我々は, 物体の 形状を認識する際，左右に咞き込むことで視認精度を向上 させる動作を“賽覗動作”とよび，画像情報に基づく物体認 識の推定精度向上に寄与する動作を発生させる窺覗動作制 御法の研究を行ってきた (2)。

文献 (2) にて提案した手法では，姿勢変化のための指令 值生成に多くの計算処理を必要とした。本稿では，近似式 を導入して計算処理量を減少させる一方で，前提案手法と 同等の動作を達成する近似型窺䙼動作制御法を提案する。

\section{2. 近似型窥悓動作制御法}

本稿における物体認識に最適な動作とは, 対象物体上の 複数の特徴点のうち基準となる特徴点を画像中央に移動さ せ，かつ，それ以外の特徽点の相対位置を最も精度良く推 定できる姿勢へカメラを移動させる動作，と定義する。

〈2・1〉 窥司見動作制御法 ${ }^{(2)} \mathrm{CCD}$ カメラを先端に取り付 けた $n$ 自由度マニピュレータ (Fig. 1)について, 画像情報を基 にカメラ姿勢を制御するビジュアルフィードバック制御系を 構成する (Fig. 2)。機構的圥長性を有するマニピュレータの 関節角速度ベクトル $\dot{\boldsymbol{q}} \in \mathfrak{R}^{n}$ と画像上の特徵点 $\boldsymbol{u}=\left[\begin{array}{ll}u & v\end{array}\right]^{T}$ の速度べクトル $\dot{\boldsymbol{u}}$ を関係づけるヤコビ行列を $\boldsymbol{J}_{i r} \in \mathfrak{R}^{2 \times n}$ とするとき，関節参照加速度 $\ddot{\boldsymbol{q}}^{r e f}$ は次式で与えられる。

$$
\ddot{\boldsymbol{q}}^{r e f}=\boldsymbol{J}_{i r}^{+} \cdot \ddot{\boldsymbol{u}}^{r e f}+\left(\boldsymbol{I}-\boldsymbol{J}_{i r}^{+} \cdot \boldsymbol{J}_{i r}\right) \cdot \ddot{\boldsymbol{q}}_{\text {pose }}^{r e f}
$$

\footnotetext{
成蹊大学大学院工学研究科電気電子工学専攻

干 180-8633 武蔵野市吉祥寺北町 3-3-1

Dept. of Electrical Eng. and Electronics, Seikei University

3-3-1, Kichijoji-Kitamachi, Musashino 180-8633
}

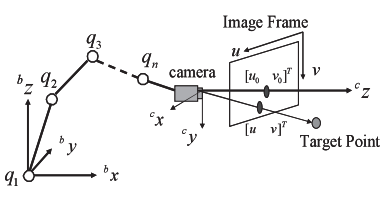

Fig. 1. Eye-in-hand robot.

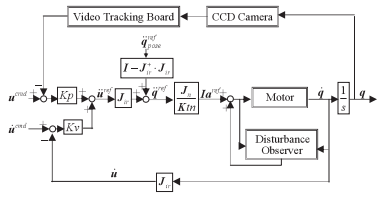

Fig. 2. Visual servo controller.

\section{ここで， $\boldsymbol{J}_{i r}^{+}$は $\boldsymbol{J}_{i r}$ の擬似逆行列，I は単位行列を表す。}

まず, 基準となる特徵点を画像中央に移動させるため, 画 像参照加速度 $\ddot{u}^{r e f}$ を PD 制御則に基づいて与える。

$$
\ddot{\boldsymbol{u}}^{r e f}=K p \cdot\left(\boldsymbol{u}^{c m d}-\boldsymbol{u}\right)+K v \cdot\left(\dot{\boldsymbol{u}}^{c m d}-\boldsymbol{u}\right) \cdot
$$

一方, 参照加速度 $\ddot{\boldsymbol{q}}_{\text {pose }}^{r e f}$ は窺䙼動作のための姿勢制御に 用いる。基準となる特徵点以外の特徴点を $k$ 個とり, 画像 上位置 $\boldsymbol{u}_{i}(i=1, \ldots, k)$ を統合した特徴点位置べクトルを $\boldsymbol{y} \equiv\left[\begin{array}{llll}\boldsymbol{u}_{\mathbf{1}}{ }^{T} & \boldsymbol{u}_{\mathbf{2}}{ }^{T} & \cdots & \boldsymbol{u}_{\boldsymbol{k}}{ }^{T}\end{array}\right] \in \mathfrak{R}^{2 k}$ とし, ヤコビ行列を統合 した拡張ヤコビ行列を $\boldsymbol{H} \equiv\left[\begin{array}{llll}\boldsymbol{J}_{i r 1}^{T} & \boldsymbol{J}_{i r 2}^{T} & \cdots & \boldsymbol{J}_{i r k}^{T}\end{array}\right] \in \mathfrak{R}^{2 k \times n}$ とする。対象物体の認識精度が高くなる動作を選択するため に, 特徵点速度ベクトルの 2 次ノルム $\|\dot{\boldsymbol{y}}\|$ の最大值を得る方 向へ特徽点を移動させる。その方向は, 行列 $\boldsymbol{H} \cdot \boldsymbol{H}^{T} \in \mathfrak{R}^{2 k \times 2 k}$ の最大固有值 $\lambda_{1}$ に対応する固有ベクトル $\boldsymbol{b}_{\mathbf{1}} \in \mathfrak{R}^{2 k}$ に等し い。そこで, 特徵点の画像上での所望速度べクトル $\dot{\boldsymbol{y}}^{d}$ es と 参照加速度 $\ddot{\boldsymbol{y}}^{r e f}$ を次式で与える。

$$
\dot{\boldsymbol{y}}^{\text {des }}=\alpha \sqrt{\lambda_{1}} \cdot \boldsymbol{b}_{\mathbf{1}}, \quad \ddot{\boldsymbol{y}}^{\text {ref }}=K \cdot\left(\dot{\boldsymbol{y}}^{\text {des }}-\dot{\boldsymbol{y}}\right) \cdots
$$

ここで $\alpha$ は速度ゲイン，Kは比例ゲインである。

$\ddot{\boldsymbol{y}}^{r e f}$ に対応するマニピュレータの関節角加速度参照值 覓ose

$$
\ddot{\boldsymbol{q}}_{\text {pose }}^{\text {ref }}=\boldsymbol{H}^{+} \cdot\left(\ddot{\boldsymbol{y}}^{\text {ref }}-\dot{\boldsymbol{H}} \cdot \dot{\boldsymbol{q}}\right)
$$

ここで $\boldsymbol{H}^{+} \in \mathfrak{R}^{n \times 2 k}$ は $\boldsymbol{H}$ の擬似逆行列である。 
$\langle\mathbf{2} \cdot \mathbf{2}\rangle$ 近似型窺覗動作制御法 固有ベクトル $\boldsymbol{b}_{\mathbf{1}}$ は大 きな行列 $\boldsymbol{H} \cdot \boldsymbol{H}^{T}$ に基づいて求めるが, $\boldsymbol{H} \cdot \boldsymbol{H}^{T}$ の最大固有 值は行列 $\boldsymbol{H}^{T} \cdot \boldsymbol{H} \in \mathfrak{R}^{n \times n}$ のそれに等しいので, $\boldsymbol{H}^{T} \cdot \boldsymbol{H}$ の 最大固有值に対応する固有べクトル $c_{1} \in \mathfrak{R}^{n}$ を利用すると (4) 式は (5) 式に書き換えることができる。

$$
\ddot{\boldsymbol{q}}_{\text {pose }}^{r e f}=K \cdot\left(\alpha \boldsymbol{c}_{\mathbf{1}}-\dot{\boldsymbol{q}}\right)-\boldsymbol{H}^{+} \cdot \dot{\boldsymbol{H}} \dot{\boldsymbol{q}}
$$

特徵点数 $k$ は増減する可能性があるが, マニピュレータ の関節数 $n$ は固定值と考えられるので，(5) 式によってより 少ない計算量での加速度参照值 $\ddot{\boldsymbol{q}}_{\text {pose }}^{\text {ref }}$ の算出が可能となる。

さらに(5) 式では $\dot{\boldsymbol{H}} \cdot \dot{\boldsymbol{q}} \propto \dot{\boldsymbol{q}}^{2}$ が成立するので，ロボット を緩やかに動作させることで右辺第二項が無視できる。ま た，第一項について，Kの值を小さく， $\alpha$ の值を大きく調 整することで，(5) 式は (6) 式に近似することができる。

$$
\ddot{\boldsymbol{q}}_{\text {pose }}^{\text {ref }}=K \cdot \alpha \boldsymbol{C}_{\mathbf{1}}
$$

これより，拡張ヤコビ行列の擬似逆行列 $\boldsymbol{H}^{+} \in \mathfrak{R}^{n \times 2 k}$ と， 微分拡張ヤコビ行列 $\dot{H} \in \mathfrak{R}^{2 k \times n}$ の計算を省くことが可能と なる。たとえば $n=3, k=20$ の場合では，(5)式に対して (6) 式ではおよそ $1 / 8$ の計算量（和積回数）になる。

この近似の妥当性と, 近似の導入による動作結果への影 響を実機実験により検証する。

\section{3. 実験}

Fig. 3 に示す水平スカラ型 3 自由度マニピュレータ $(n=3)$ を用い，特徵点として基準点を 1 個，その他の特徽点を 2 個設けた $(k=2)$ 。また, Table 1 に制御パラメータを示す。

〈3・1〉 シミュレーション 姿勢制御を考慮せずに基 準特徵点を画像中央へ移動することのみを目的とした動作 制御と，窺瞀動作制御法，そして近似型窺覗動作制御法に 基づくシミュレーションを行った。それぞれ Fig. 4 Fig. 6 に結果を示す。なお, 各図とも (a) に特徵点の画像上座標, (b) に画像上の特徴点移動速度べクトルの 2 次ノルム $\|\dot{\boldsymbol{y}}\|$ を 示す。いずれの場合も (a)より，基準特徵点を画像中央に 移す動作が達成されていることがわかる。一方，(b)より， 姿勢制御則を与えない場合に比べて，窺司見動作制御と近似 型窥瞀動作制御では結果がほぼ一致しており，特徵点移動 速度べクトルが大きくなり, 姿勢変化量あたりの特徵点移 動変化量が大きくなるようロボットが制御され，対象物を 認識しやすい方向へカメラが姿勢制御されことがわかる。

次に, マニピュレータの関節の動きと画像上の特徴点に おける画像可操作度 $\omega$ を Fig. 7 に示す。画像可操作度が大 きいとき，わずかな関節の動きにおいて画像上の特徽点を 大きく動かすことができる。すなわち，関節角あたりの画 像解像度が向上し，対象物の推定位置精度が向上する。

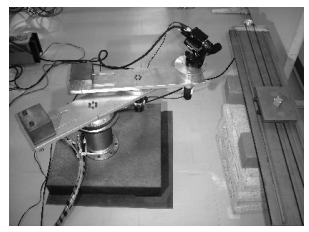

Fig. 3. Eye-in-hand robot.
Table 1. Controller parameter.

\begin{tabular}{|c|c|c|}
\hline Position feedback gain & $K p$ & 0.1 \\
\hline Velocity feedback gain & $K v$ & 0.63 \\
\hline Observer gain & $g$ & 200 \\
\hline Posture transient gain & $K$ & $1.0 \times 10^{-2}$ \\
\hline Posture transient gain & $\alpha$ & $1.0 \times 10^{-8}$ \\
\hline
\end{tabular}

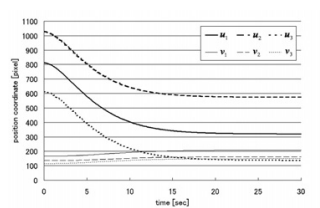

(a) Feature points transition

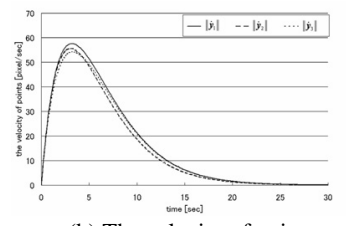

(b) The velocity of points
Fig. 4. Simulation results by conventional method.

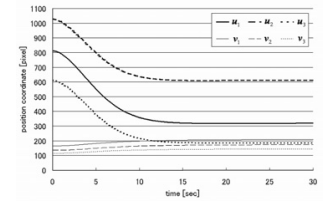

(a) Feature points transition

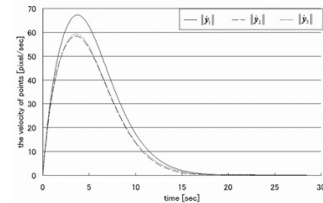

(b) The velocity of points
Fig. 5. Simulation results by exploring motion control.

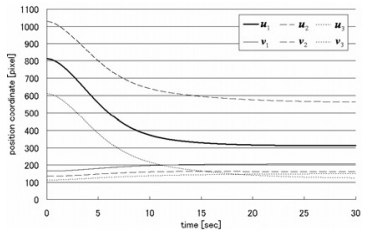

(a) Feature points transition

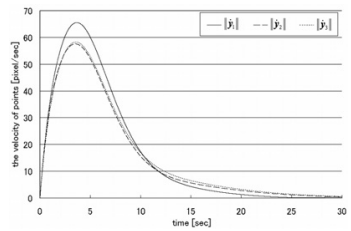

(b) The velocity of points
Fig. 6. Simulation results by proposed method.
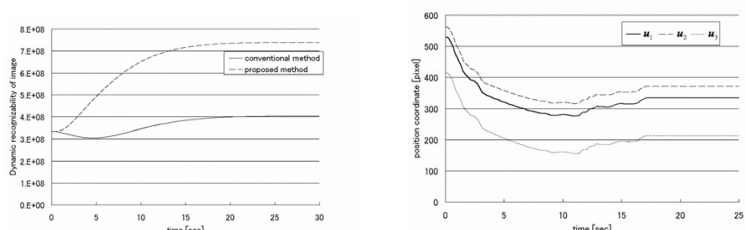

Fig. 7. Visual manipulability. Fig. 8. Experimental result.

Fig. 7 より，姿勢制御則を与えない場合と比べ，近似型 窺覗動作制御ではマニピュレータの姿勢変化に対する画像 上の特徵点可到達域が大きくなることがわかる。

$\langle\mathbf{3} \cdot \mathbf{2}\rangle$ 実機実験 制御パラメータは $K p=2.0, K v=$ 4.24, その他のパラメータはシミュレーションと同様とした。 制御用 PC の OS は RT-Linux, 制御サンプル時間は 1 [msec], 画像情報のサンプル時間は $8.3[\mathrm{msec}]$ とした。Fig. 8 に実 験結果として，画像中の特徵点 (3 点) の推移を示す。基準 となる特徴点 $\boldsymbol{u}_{1}$ が画像中央へ到達できたことから, 正確な ビジュアルフィードバック制御が達成され，マニピュレー 夕の姿勢変化と特徴点の動作量の関係に基ついて常に対象 物体を認識しやすい方向へ動作しながら安定姿勢に至った。

\section{4. 結 論}

本研究では，画像情報に基づく対象物の推定精度を向上 させる姿勢制御則について，姿勢変化のための指令值生成 において近似を導入することで計算処理量を削減した。シ ミュレーションと実験結果よりその有効性を確認した。

(平成 18 年 3 月 31 日受付，平成 18 年 9 月 11 日再受付)

$$
\text { 文献 }
$$

(1) S. Hutchinson, G.D. Hager, and P.I. Corke: "A Tutorial on Visual Servo Control", IEEE Transaction on robotics and automation, Vol.12, No.5, pp.651670 (1996)

(2) M. Ichikawa, S. Motoki, and M. Shibata: "Exploring motion control for three-dimensional object recognition based on eye-in-hand visual servoing", T. IEE Japan, Vol.126-D, No.6, pp.726-731 (2006-6) (in Japanese) 市川麻理子・元木 聡・柴田昌明：「ハンドアイビジョンシステム による 3 次元物体認識のための窺柕動作制御法」, 電学論 $\mathrm{D}, \mathbf{1 2 6}, 6$, pp.726-731 (2006-6) 